\title{
Epidemien, Drogen und Prävention: hochemotionale Themen!
}

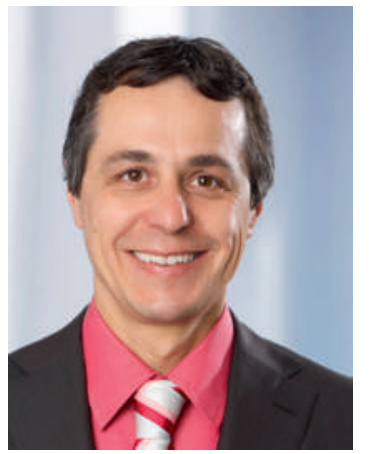

Der Krieg zwischen den Krankheitserregern und dem Menschen tobt seit Urzeiten: So wie die Wellen gegen die Küste branden, wirken Keime unablässig auf unsere Existenz ein. Epidemien beschäftigen unseren Bundesstaat seit seiner Gründung im Jahr 1848. Während der Frühjahrssession der eidgenössischen Räte standen sie einmal mehr im Zentrum der politischen Debatte: Zum zweiten Mal seit seiner Einführung am 2. Juli 1886 haben wir das Bundesgesetz über die Bekämpfung übertragbarer Krankheiten des Menschen (10.107) umfassend revidiert. In einem Umfeld bedeutender wissenschaftlicher Entdeckungen (1876 wies Robert Koch die Kausalität zwischen dem Milzbranderreger und der Krankheit nach) verabschiedete das Parlament vor 136 Jahren das erste Epidemiengesetz. Im Wissen darum, dass Krankheitserreger vor politischen Grenzen nicht Halt machen, hatten die Kantone diese Aufgabe dem Bund übertragen. Eine Folge des Epidemiengesetzes war etwa die Einführung von Kantonsärzten. Eine schwere Typhusepidemie im Jahre 1963 in Zermatt mit über 400 Erkrankten und mehreren Toten führte 1970 zur ersten Totalrevision. Anschliessend folgten mehrere Teilrevisionen bis zu dieser zweiten Totalrevision, die notwendig ist, damit wir den Bedrohungen im 21. Jahrhundert gewachsen sind.

Das neue Gesetz enthält ein Modell mit drei Ebenen, abhängig davon, ob es sich um eine normale, eine besondere oder eine ausserordentliche Lage handelt. Es überträgt dem
Mehrheit, so dass die Kantone nun in einer normalen Lage Impfungen in ihrem Zuständigkeitsgebiet nicht mehr für obligatorisch erklären können. Im Gesetz bleibt die Möglichkeit dazu verankert, aber nur in einer besonderen Lage und bei einem entsprechenden Bundesratsbeschluss. Ebenso stieg der Dezibelpegel im Saal an, als es um die Änderung der Strafnorm zum Verbreiten menschlicher Krankheiten ging. Die in der Schweiz verhängten Sanktionen für die Verbreitung von HIV/Aids lösten eine lebhafte Diskussion aus. Die Bestimmung wurde dahingehend geändert, als eine Person neu nicht mehr strafbar ist, sofern sie die andere Person vor der Übertragung über das konkrete Ansteckungsrisiko in Kenntnis gesetzt hat. Das Epidemiengesetz wurde schliesslich von einer grossen Mehrheit des Nationalrats (152 gegen 4 Stimmen) angenommen. Die FMH begrüsst diesen Entscheid.

Ein anderes spannendes Thema war das Präventionsgesetz (09.076). Nach dem Nichteintretensentscheid des Ständerats vom Dezember 2011 musste sich der Nationalrat erneut mit dieser Frage befassen. Glücklicherweise (aus Sicht der FMH) bekräftigte eine Mehrheit von 106 gegen 79 Stimmen die Absicht, dieses Gesetz zu schaffen, um die Wirkung der Prävention zu verbessern. Somit muss sich im Juni der Ständerat erneut zu dieser Frage äussern. Ein JA würde ein entsprechendes Gesetz ermöglichen, während ein NEIN definitiv wäre und ... man dann vielleicht 2030 wieder darüber beraten würde!

Eine weitere faszinierende Angelegenheit war die Revision des Betäubungsmittelgesetzes, insbesondere die Frage des Cannabiskonsums (04.439). Die Idee der CVP Schweiz, für die Bestrafung des Cannabiskonsums von Erwachsenen Ordnungsbussen (wie im Strassenverkehr) einzuführen, fand im Nationalrat trotz des entschiedenen Widerstands der SVP

\section{Das neue Epidemiengesetz überträgt dem Bund mehr Kompetenzen. \\ Dieser muss nationale strategische Ziele festlegen und alle Massnahmen koordinieren, während die Kantone weiterhin für den Vollzug zuständig sind.}

Bund (BAG) mehr Kompetenzen. Dieser muss nationale strategische Ziele festlegen und alle Massnahmen koordinieren, während die Kantone weiterhin für den Vollzug zuständig sind. Die Grundsätze der Selbstbestimmung und Eigenverantwortung sind im Gesetz ausdrücklich festgehalten. Während der Debatte im Nationalrat gingen zwei Mal die Emotionen hoch: bei den Impfbestimmungen und beim Art. 231 Ziff. 1 des Schweizerischen Strafgesetzbuchs (Verbreiten gefährlicher übertragbarer menschlicher Krankheiten). Die klassischen Argumente der Impfgegner, die in allen Parteien aber vermehrt bei der Ratslinken - vertreten sind, fanden eine eine Mehrheit von 111 gegen 65 Stimmen. Die Ordnungsbusse wurde auf 200 Franken festgelegt und soll nur dann angewandt werden, wenn der Konsument nicht mehr als $10 \mathrm{~g}$ Cannabis auf sich trägt. Bei allen anderen Fällen kommt weiterhin das ordentliche Strafverfahren zur Anwendung. Die Strafbarkeit des Konsums wird somit beibehalten, doch die Art der Bestrafung wird geändert! Das ist eine kleine Revolution: Ich bin gespannt auf die Entscheide des Ständerats. Die FMH unterstützt diese Stossrichtung.

Dr. med. Ignazio Cassis, Vizepräsident der FMH und Nationalrat 